\title{
Deformation Analysis of LRC Underground Gas Storage
}

\author{
Primož Jelušič and Bojan Žlender \\ Faculty of Civil Engineering, University of Maribor, Smetanova 17, SI-2000 Maribor, Slovenia
}

\begin{abstract}
The risk during construction and in the operation of the underground gas storage (UGS) was analyzed. One of most important risk which should be prevented is large deformation or destruction of the steel lining. The specific deformation of the steel lining needs to be inside the acceptable value. This paper presents lined rock cavern (LRC) concept and specific deformations, which can occur under operation of underground gas storage. Analysis is performed with different (3D model and axis symmetrical) FEM models and analytical model. We made a comparison between analytical calculation and FEM calculation. Concrete wall is mechanically not regarded as reinforced concrete structure which means that concrete will crack. Finally, we determined the minimum value of Young's modulus, which satisfies the condition of maximum deformation of steel lining.
\end{abstract}

Key words: Underground gas storage, lined rock cavern, interaction concrete-rock, rock mass properties, rock mechanics.

\section{Introduction}

The LRC concept has been developed in Sweden since mid 1980 s by Sydkraft as the coordinator. The obvious purpose of storage is to balance supply of natural gas with the variations in consumption. There are also other purposes that storage can fulfill like e.g. strategic role with security of delivery and possibilities to buy and sell gas. The principal idea behind the LRC gas-storage concept is to rely on a rock mass to serve as a pressure vessel in containing stored natural gas. Storage caverns are excavated in rock as vertical cylinders [1]. The mechanical response of the cavern wall to the LRC pressure depends on the site-specific character of the rock mass and on the structural interaction between the rock mass and concrete liner. The risk during construction and in the operation of the system should be analyzed. One of most important risk which should be prevented is large deformation or destruction of the steel lining. In order to evaluate strain of steel liner different geomechanical models were built. A FEM analysis consists a set of calculations for different mechanical properties for given geometry of cavern and gas pressure. The rock mass as construction

Corresponding author: Bojan Žlender, $\mathrm{PhD}$, professor, research fields: geotechnical engineering, soil mechanics. E-mail: bojan.zlender@uni-mb.si. material and engineering design of underground structures involves different types of uncertainties. All this implies that predictions concerning the rock mass deformation and security risks are difficult. This paper presents specific deformations, which can occur under operation of underground gas storage.

\section{Lined Rock Cavern Components}

The LRC design is based on the combination of a few key components [2]:

(1) The surrounding rock mass to absorb the forces (geomechanical rock parameters).

(2) A concrete layer serving as a base for the lining and as a load transfer media between the gas pressure forces and the rock.

(3) A thin lining enclosing the gas in the cavern.

(4) Geometry of cavern (depth, shape, diameter and height).

(5) Mechanical properties of LRC materials.

(6) Loads (external rock pressure, internal gas pressure).

(7) Drainage system between the cavern wall and rock mass.

\subsection{Cavern Wall}

Cavern wall (Fig. 1) is composed of several elements [3]: 

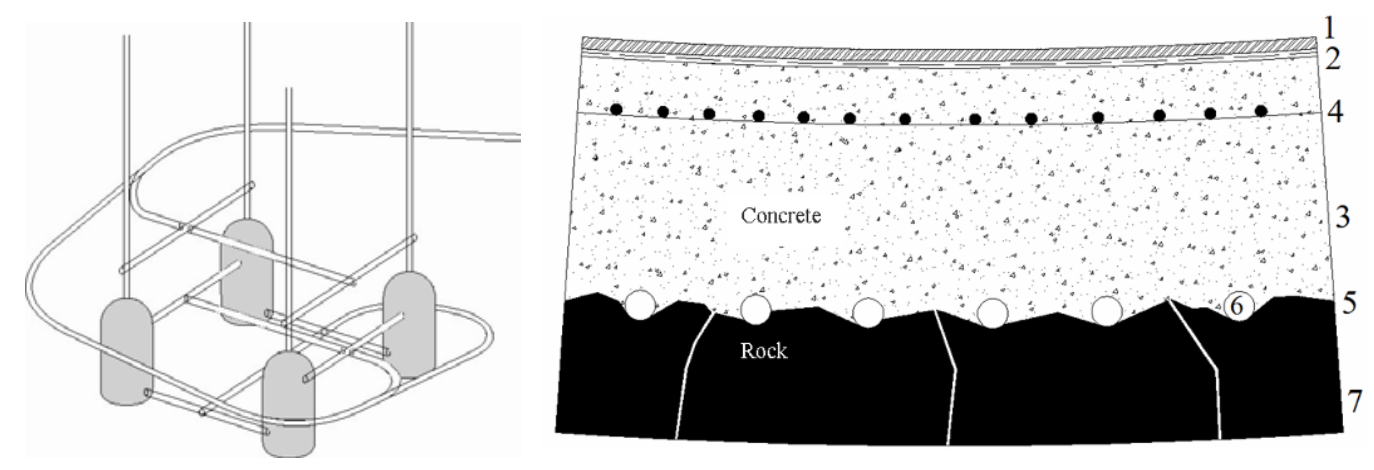

Fig. 1 Storage caverns (left), structure of cavern wall (right).

(1) The steel liner is made of carbon steel. The role of the steel liner is to achieve gas tightness. It has no pressure absorbing function but it is able to bridge minor cracks in the concrete.

(2) Membrane lining for reducing friction on the contacting steel-concrete and for corrosion protection of steel.

(3) Concrete lining between the steel lining and rock, for putting the pressure of the gas into rock. Concrete lining (self compacting concrete) distributes the deformations uniformly and in the same time it will serve as a smooth base for the steel liner.

(4) Reinforcement (welded mesh) to prevent tangential deformations.

(5) Layer of special low strength permeable shotcrete is placed closest to the rock surface. The purpose of the shotcrete is to protect the drainage system.

(6) Drainage system.

(7) Rock.

\subsection{Cavern Size and Shape}

Caverns have a shape of vertical cylinder with rounded bottom and semi-spherical roof. Cavern size can change in terms of diameter, high, depths and thickness of concrete. In FEM analysis we construct cavern with diameter $25 \mathrm{~m}$, height $75 \mathrm{~m}$, rock cover $150 \mathrm{~m}$ and $2 \mathrm{~m}$ thick concrete wall.

\subsection{Loadings}

The external pressure acts on the wall of the cavern (during the construction and operation). The internal pressure is beginning to occur in service. It is expected that the pressure of gas during periods of gas supply and discharge cyclically increased and fell between the values of $3 \mathrm{MPa}$ and a maximum value $25 \mathrm{MPa}$. The internal load is therefore static and cyclic. Lifetime caverns is limited to the minimum 500 cycles.

\section{Risk Assessment}

Risks during the construction:

- Risk C1: Large scale failure of rock cover;

- Risk C2: Large deformations;

- Risk C3: Irruption of water;

- Risk C4: Impact on water resources in the area.

Risks during construction are typical as they occur in the construction of the tunnel. They depend on the geological conditions and hydrological conditions and geomechanical rock properties in the surroundings of LRC.

Risks during the operation:

- Risk O1: Raising of rock cover;

- Risk O2: Failure of rock mass (rock strength is exceeded);

- Risk O3: Unequally deformation of the LRC structure, because of the rock heterogeneity;

- Risk O4: Draining system does not work;

- Risk O5: Instability (failure) of rock between two caverns;

- Risk O6: Large deformation or destruction of the steel lining; 
- Risk 07: To high increasing deformation due to cyclic loads;

Geological conditions (heterogeneity, orientation layers,) and hydro geological conditions and geomechanical rock properties around LRC significant impact on risks.

\section{Deformation Analysis}

In order to calculate the strain of Cavern wall, we made analytical calculation and calculation using FEM in the elastic material. Then we calculated strains in the plastic material. Impact of the axial distance between the caverns on the specific strain is shown on the $3 \mathrm{D}$ model. In all models it is assumed that the concrete lining cracks and cannot withstand any hoop forces. Input parameters are shown in Table 1.

\subsection{Analytical Procedure to Calculate Stress and Strain of Cavern in Linear Elastic Material}

In two dimensions the equations of equilibrium in cylindrical coordinates may be written down with Eqs. (1) and (2).

$$
\begin{aligned}
& \frac{\partial \sigma_{r}}{\partial r}+\frac{1}{r} \frac{\partial \tau \theta_{r}}{\partial \theta}+\frac{\sigma_{r}-\sigma_{\theta}}{r}+\rho R=0 \\
& \frac{\partial \tau_{r} \theta}{\partial r}+\frac{1}{r} \frac{\partial \sigma \theta}{\partial \theta}+\frac{2 \tau_{r} \theta}{r}+\rho \Theta=0
\end{aligned}
$$

\begin{tabular}{|c|c|c|}
\hline Rock & & \\
\hline Density & $\rho$ & $2.6 \mathrm{~g} / \mathrm{cm}^{3}$ \\
\hline Young modulus & $\mathrm{E}$ & $5 \mathrm{GPa}$ to $35 \mathrm{GPa}$ \\
\hline Poisson ratio & $v$ & 0.2 \\
\hline Cohesion & $\mathrm{c}$ & $0.7 \mathrm{MPa}$ to $1.6 \mathrm{MPa}$ \\
\hline Shear angle & $\varphi$ & $37.5^{\circ}$ to $45.5^{\circ}$ \\
\hline Dilatation angle & $\psi$ & $9^{\circ}$ \\
\hline \multicolumn{3}{|l|}{ Structure } \\
\hline Steel & $\mathrm{t}_{\text {steel }}$ & $15 \mathrm{~mm}$ \\
\hline Concrete & $\mathrm{t}$ & $2 \mathrm{~m}$ \\
\hline \multicolumn{3}{|l|}{ Geometry } \\
\hline Depth of LRC (rock cover) & $\mathrm{d}$ & $150 \mathrm{~m}$ \\
\hline Inner diameter of LRC & $\mathrm{D}$ & $25 \mathrm{~m}$ \\
\hline Inner height of LRC & $\mathrm{H}$ & $75 \mathrm{~m}$ \\
\hline \multicolumn{3}{|l|}{ Loadings } \\
\hline Vertical Rock pressure & $\sigma_{\mathrm{z}}$ & 3.9-5.8 MPa \\
\hline Gas pressure of full cavern & $\mathrm{p}_{\max }$ & $20 \mathrm{MPa}$ \\
\hline
\end{tabular}

Table 1 Input parameters.
Since all quantities are independent of $\mathrm{r}$ and $\mathrm{z}$, the stress-Eq. (1) gives.

$$
\frac{\partial \sigma_{r}}{\partial r}+\frac{\sigma_{r}-\sigma_{\theta}}{r}=0
$$

The stress-strain relations for the case of plane strain may be written [4].

$$
\begin{gathered}
\sigma_{r}=(\lambda+2 \mathrm{G})_{\varepsilon_{r}}+\lambda \varepsilon_{\theta}=(\lambda+2 \mathrm{G}) \frac{\mathrm{du}}{\mathrm{dr}}+\frac{\lambda \mathrm{u}}{\mathrm{r}} \\
\sigma_{\theta}=(\lambda+2 \mathrm{G})_{\varepsilon_{\theta}}+\lambda \varepsilon_{r}=\lambda \frac{\mathrm{du}}{\mathrm{dr}}+\frac{(\lambda+2 \mathrm{G}) \mathrm{u}}{r}
\end{gathered}
$$

Using (4) and (5) in (3) gives

$$
\frac{\mathrm{d}^{2} \mathrm{u}}{\mathrm{dr}^{2}}+\frac{1}{r} \frac{\mathrm{du}}{\mathrm{dr}}-\frac{\mathrm{u}}{\mathrm{r}^{2}}=0
$$

This may be written

$$
\frac{\mathrm{d}}{\mathrm{dr}}\left(\frac{\mathrm{du}}{\mathrm{dr}}+\frac{\mathrm{u}}{\mathrm{r}}\right)=0
$$

The general solution of (6) is

$$
\mathrm{u}=\mathrm{Ar}+\frac{\mathrm{B}}{\mathrm{r}}
$$

Where $\mathrm{A}$ and $\mathrm{B}$ are constants which have to be found from the boundary conditions. For inner pressure $p_{1}$ and outer pressure $p_{2}$ it follows:

$$
\sigma_{\mathrm{r}}=\mathrm{p}_{1} \text {, when } \mathrm{r}=\mathrm{R}_{1} ; \sigma_{\mathrm{r}}=\mathrm{p}_{2} \text {, when } \mathrm{r}=\mathrm{R}_{2}
$$

Substituting (7) in (4) gives, using (8),

$$
2 \mathrm{~A}(\lambda+\mathrm{G})-2 \mathrm{~GB} / \mathrm{R}_{1}{ }^{2}=\mathrm{p}_{1} ; 2 \mathrm{~A}(\lambda+\mathrm{G})-2 \mathrm{~GB} / \mathrm{R}_{2}{ }^{2}=\mathrm{p}_{2}(9)
$$

Solving gives

$$
\mathrm{A}=\frac{\mathrm{p}_{2} \mathrm{R}_{2}{ }^{2}-\mathrm{p}_{1} \mathrm{R}_{1}{ }^{2}}{2(\lambda+\mathrm{G})\left(\mathrm{R}_{2}{ }^{2}-\mathrm{R}_{1}{ }^{2}\right)}, \mathrm{B}=\frac{\left(\mathrm{p}_{2}-\mathrm{p}_{1}\right) \mathrm{R}_{1}{ }^{2} \mathrm{R}_{2}{ }^{2}}{2 \mathrm{G}\left(\mathrm{R}_{2}{ }^{2}-\mathrm{R}_{1}{ }^{2}\right)}(10)
$$

So that finally from (7), (4), and (5),

$$
\begin{gathered}
\mathrm{u}=\frac{\left(\mathrm{p}_{2} \mathrm{R}_{2}{ }^{2}-\mathrm{p}_{1} \mathrm{R}_{1}{ }^{2}\right) \mathrm{r}}{2(\lambda+\mathrm{G})\left(\mathrm{R}_{2}{ }^{2}-\mathrm{R}_{1}{ }^{2}\right)}+\frac{\left(\mathrm{p}_{2}-\mathrm{p}_{1}\right) \mathrm{R}_{1}{ }^{2} \mathrm{R}_{2}{ }^{2}}{2 \mathrm{G}\left(\mathrm{R}_{2}{ }^{2}-\mathrm{R}_{1}{ }^{2}\right) \mathrm{r}} \\
\sigma_{\mathrm{r}}=\frac{\left(\mathrm{p}_{2} \mathrm{R}_{2}{ }^{2}-\mathrm{p}_{1} \mathrm{R}_{1}{ }^{2}\right)}{\left(\mathrm{R}_{2}{ }^{2}-\mathrm{R}_{1}{ }^{2}\right)}-\frac{\left(\mathrm{p}_{2}-\mathrm{p}_{1}\right) \mathrm{R}_{1}{ }^{2} \mathrm{R}_{2}{ }^{2}}{\mathrm{r}^{2}\left(\mathrm{R}_{2}{ }^{2}-\mathrm{R}_{1}{ }^{2}\right)} \\
\sigma_{\theta}=\frac{\left(\mathrm{p}_{2} \mathrm{R}_{2}{ }^{2}-\mathrm{p}_{1} \mathrm{R}_{1}{ }^{2}\right)}{\left(\mathrm{R}_{2}{ }^{2}-\mathrm{R}_{1}{ }^{2}\right)}+\frac{\left(\mathrm{p}_{2}-\mathrm{p}_{1}\right) \mathrm{R}_{1}{ }^{2} \mathrm{R}_{2}{ }^{2}}{\mathrm{r}^{2}\left(\mathrm{R}_{2}{ }^{2}-\mathrm{R}_{1}{ }^{2}\right)}
\end{gathered}
$$

To calculate stresses and strain of cavern in linear elastic material we use four steps:

(1) Load internal pressure of gas $\left(\mathrm{p}_{1}\right)$

(2) Insert $R_{2} \rightarrow \infty$ and Eq.s (11), (12) and (13) gives

$$
\mathrm{u}=\frac{\mathrm{p}_{2} \mathrm{r}}{2(\lambda+\mathrm{G})}+\frac{\left(\mathrm{p}_{2}-\mathrm{p}_{1}\right) \mathrm{R}_{1}^{2}}{2 \mathrm{Gr}}
$$




$$
\begin{aligned}
& \sigma_{\mathrm{r}}=\mathrm{p}_{2}\left(1-\frac{\mathrm{R}_{1}^{2}}{\mathrm{r}^{2}}\right)+\frac{\mathrm{p}_{1} \mathrm{R}_{1}^{2}}{\mathrm{r}^{2}} \\
& \sigma_{\theta}=\mathrm{p}_{2}\left(1+\frac{\mathrm{R}_{1}^{2}}{\mathrm{r}^{2}}\right)-\frac{\mathrm{p}_{1} \mathrm{R}_{1}^{2}}{\mathrm{r}^{2}}
\end{aligned}
$$

(3) Calculate $p_{2}$, which is a function of depth $(\mathrm{H})$

$$
\mathrm{p}_{2}=\sigma_{\mathrm{H}}=\frac{\mathrm{v}}{(1-\mathrm{v})} \sigma_{\mathrm{v}}=\frac{\mathrm{v}}{(1-\mathrm{v})} \mathrm{v} \cdot \mathrm{H}
$$

(4) Insert $p_{2}$ in equations (14), (15) and (16).

\subsection{Comparison between Analytical Calculation and the Calculation by Using FEM}

The comparison between analytical calculation and the calculation by using FEM [5] is shown in Figs. 2-3. Notice that the curves coincide. Comparison is made for cavern with diameter $25 \mathrm{~m}$, depth $150 \mathrm{~m}$, thickness of concrete liner $2 \mathrm{~m}$ and internal pressure $20 \mathrm{MPa}$.

\subsection{Rock Mass Parameters in Terms of the} Mohr-Coulomb Failure Criterion
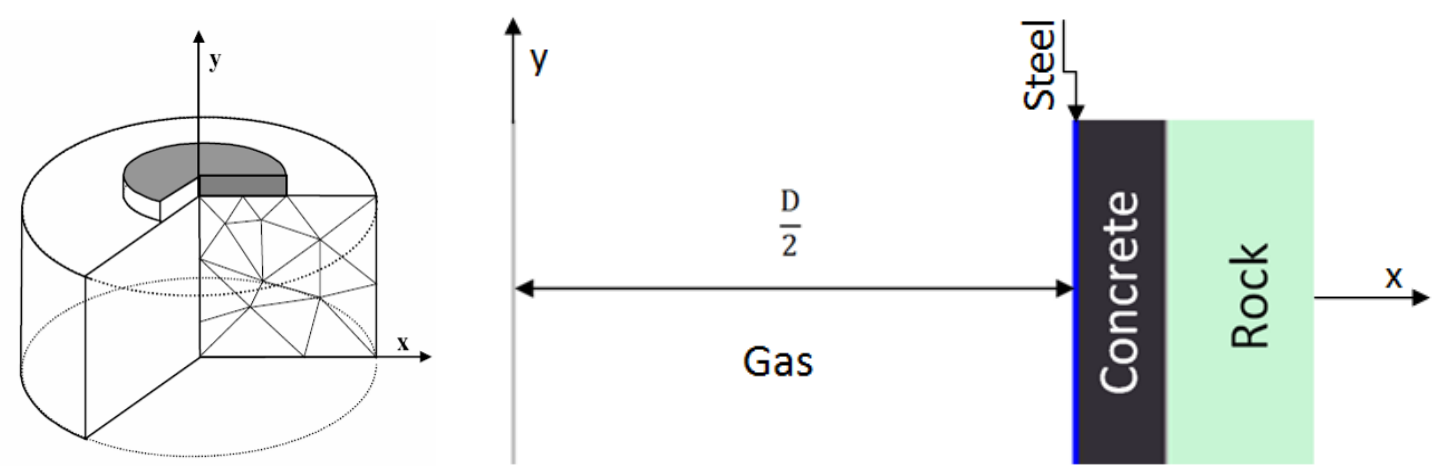

Plasticity is associated with the development of irreversible strains. In order to evaluate whether or not plasticity occurs in a calculation, a yield function, $f$, is introduced as a function of stress and strain. A perfectly-plastic model is a constitutive model with a fixed yield surface, i.e., a yield surface that is fully defined by model parameters and not affected by (plastic) straining.

The Mohr-Coulomb model involves five input parameters, i.e., $E$ and $v$ for soil elasticity; $\varphi$ and $c$ for soil plasticity and $\psi$ as an angle of dilatancy. Besides the five model parameters mentioned above, initial soil conditions play an essential role in most soil deformation problems. Initial horizontal soil stresses have to be generated by selecting proper $K_{0}$ values.

Since most geotechnical software is still written in terms of the Mohr-Coulomb failure criterion, it is necessary to determine equivalent angles of friction and cohesive strengths for each rock mass and stress

Fig. 2 Example of a axisymmetric problem.

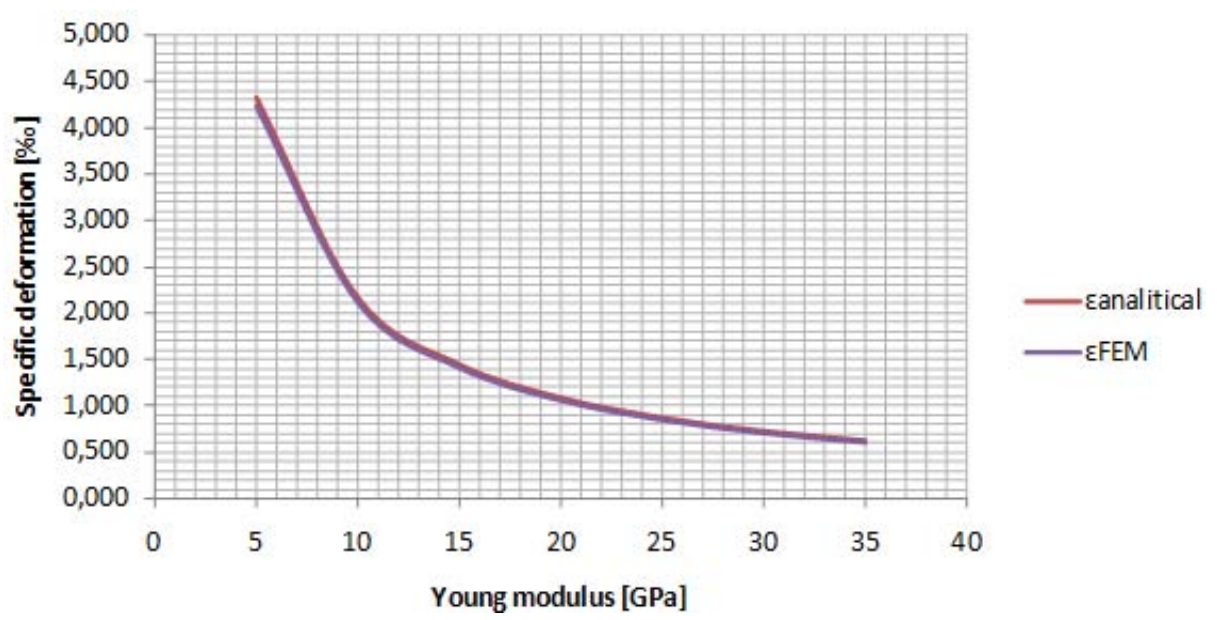

Fig. 3 Specific deformation of steel liner vs. Young modulus. 
range. Basic rock mass parameters are assessed according to RocLab. RocLab is a software program for determining rock mass strength parameters, based on the generalized Hoek-Brown failure criterion. The program RocLab provides a simple and intuitive implementation of the Hoek-Brown failure criterion, allowing users to easily obtain reliable estimates of rock mass properties, and to visualize the effects of changing rock mass parameters, on the failure envelopes [6]. The Generalized Hoek-Brown strength parameters of a rock mass $\left(m_{b}, s\right.$ and $\left.a\right)$ [7] are based on the following input data:

- Unconfined compressive strength of intact rock $\sigma_{\mathrm{ci}}$

- The intact rock deformation modulus $\mathbf{E}_{\mathbf{i}}$;

- The intact rock parameter $\mathbf{m}_{\mathbf{i}}$;

- The geological strength index GSI;

- The disturbance factor $\mathbf{D}$;

The following rock mass parameters are calculated from input data [8]:

- Rock mass tensile strength $\boldsymbol{\sigma}_{\mathbf{t}}$;

- Uniaxial rock mass compressive strength $\boldsymbol{\sigma}_{\mathbf{c}}$;

- Global rock mass compressive strength $\sigma_{\mathrm{cm}}$;
- Rock mass deformation modulus $\mathbf{E}_{\mathbf{r m}}$.

We calculate equivalent Mohr-Coulomb strength parameters (cohesion and friction angle). Different ground types are presented in Table 2.

\subsection{Comparison between 2D Axisymmetric Model and 3D Model}

Strain calculated by the axisymmetric model is consistent with 3D models as shown in Fig. 4. Both models use Mohr-Coulomb failure criterion. If we add the strain calculated in a linear elastic material we can see significantly lower strains than in the plastic material. Difference becomes smaller when Rock parameters are higher.

\subsection{UGS with Four Caverns}

UGS usually consists four caves in a relatively small distance, so it is necessary to take into account the adjacent storage. There are various cases of loading in the case of the interaction of four caverns. The critical loading case is when one cavern have maximum inner pressure $p_{i, \max }$ and other three caverns have minimum inner pressure $p_{i, m i n}$.

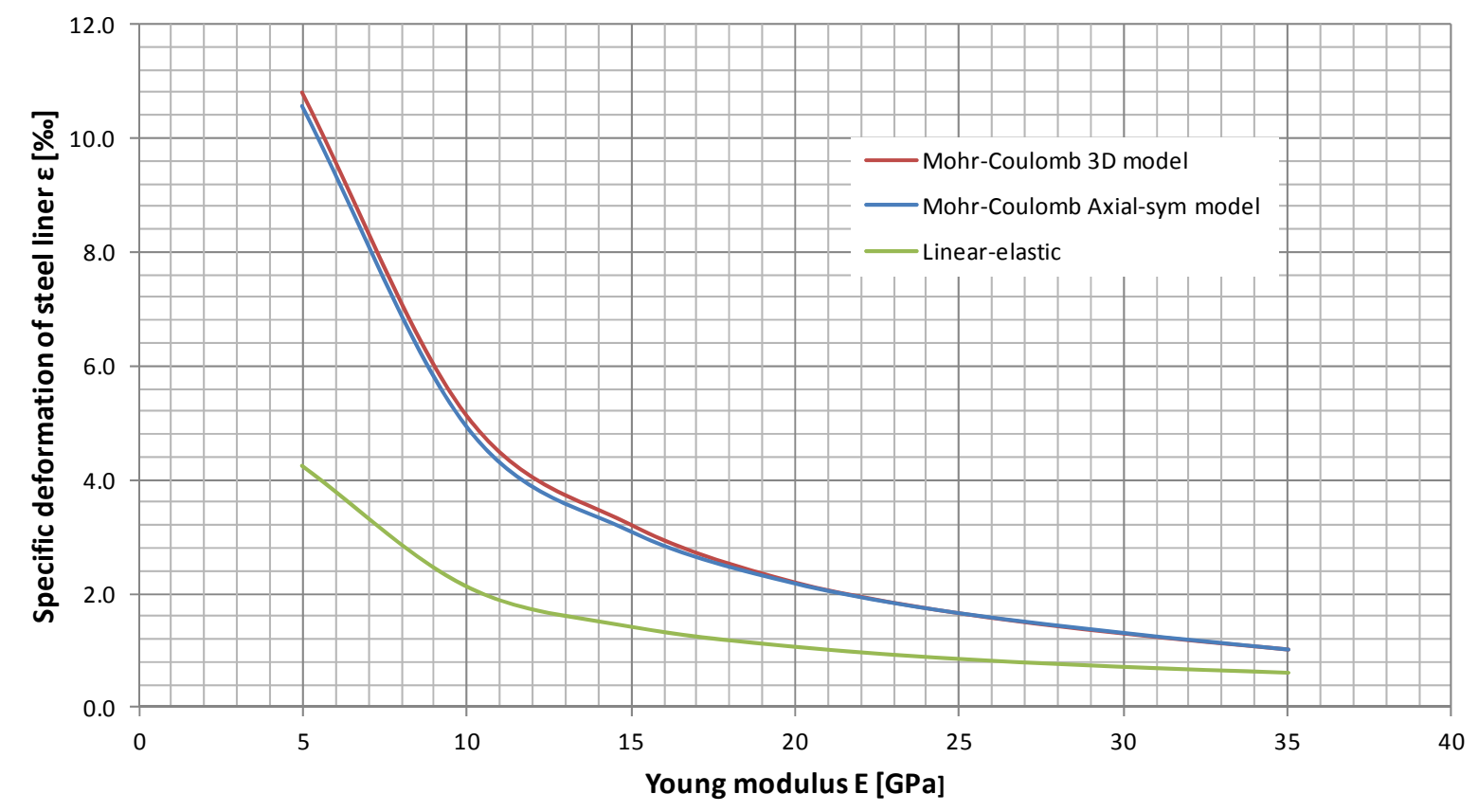

Fig. 4 Specific deformation of steel liner vs. Young modulus. 
Table 2 Ground types in terms of the Mohr-Coulomb failure criterion.

\begin{tabular}{|c|c|c|c|}
\hline Ground type & $\mathrm{E}[\mathrm{GPa}]$ & $\mathrm{c}[\mathrm{kPa}]$ & $\varphi\left[^{\circ}\right]$ \\
\hline Type 1 & 5 & 700 & 37.5 \\
\hline Type 2 & 10 & 870 & 39.0 \\
\hline Type 3 & 15 & 1000 & 41.0 \\
\hline Type 4 & 20 & 1180 & 42.5 \\
\hline Type 5 & 25 & 1280 & 43.5 \\
\hline Type 6 & 30 & 1380 & 44.5 \\
\hline Type 7 & 35 & 1600 & 45.5 \\
\hline
\end{tabular}

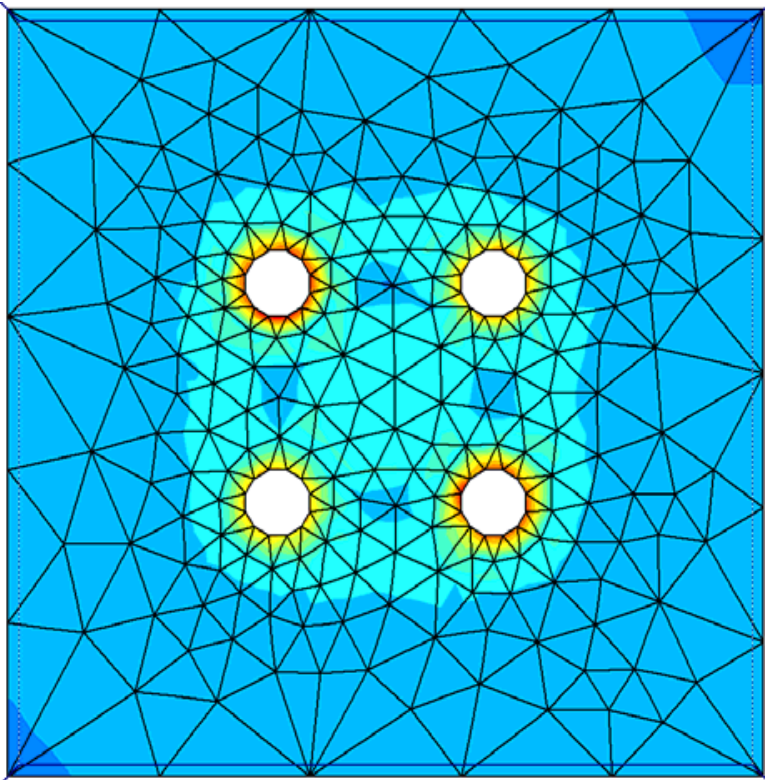

(a)
Axial distance between caverns has a significant impact on the calculation of strain. Results are shown in Figs. 5-6. Comparison is made for cavern with diameter $25 \mathrm{~m}$, depth $150 \mathrm{~m}$, thickness of concrete liner $2 \mathrm{~m}$ and internal pressure $20 \mathrm{MPa}$.

\section{Conclusion}

The linear elastic model is usually inappropriate to model the highly non-linear behavior of rock. However,

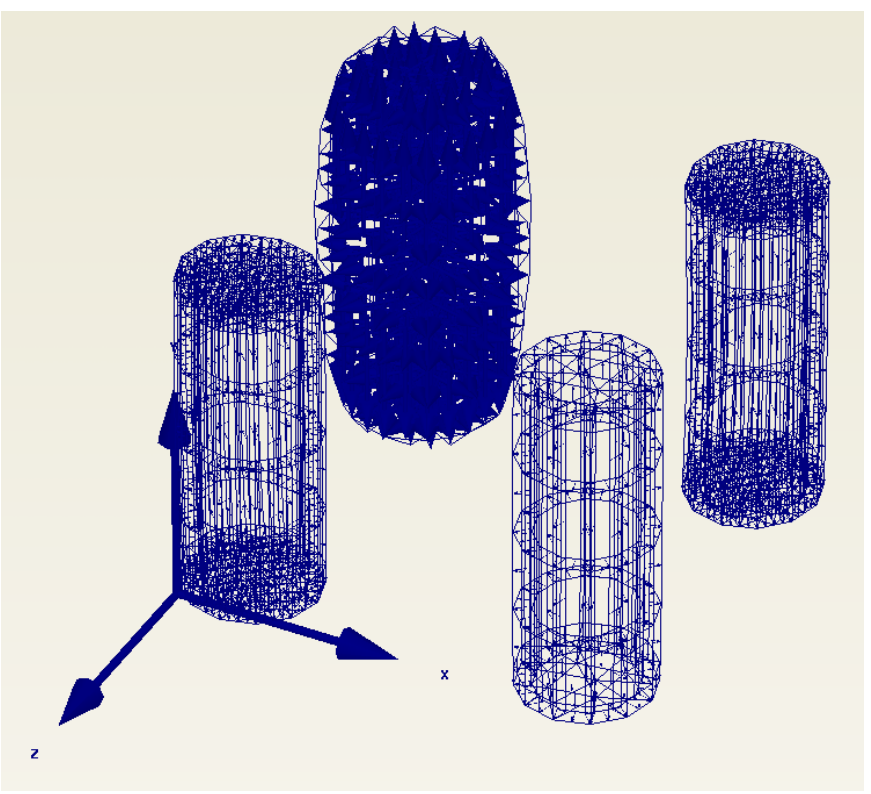

(b)

Fig. 5 (a) Plan view, (b) 3D FEM model.

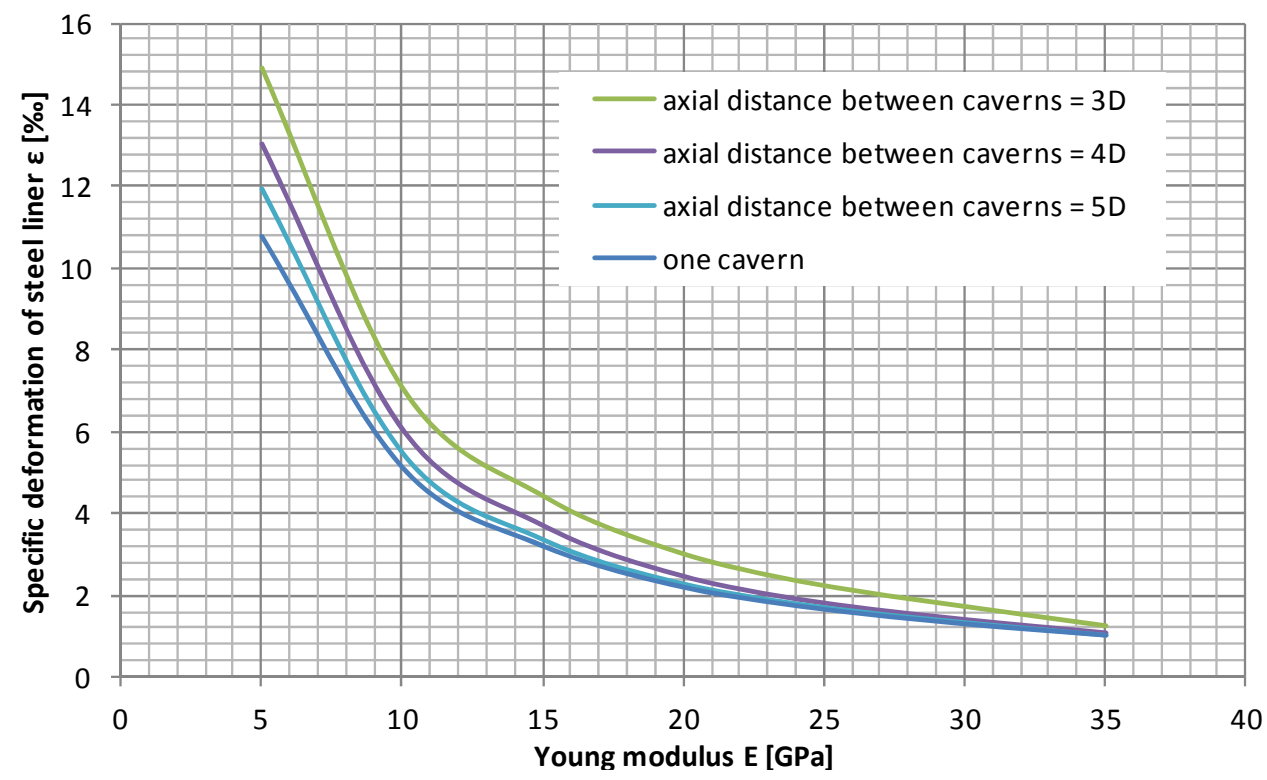

Fig. 6 Specific deformation of steel liner vs. young modulus. 
by comparing the analytical and FEM model, it can be seen that the FEM model gives us good results. With Mohr-Coulomb model, we calculated the strains that are even more realistic. It also outlines the impact of the axial distance between the caverns in the case of interaction of four caverns. For smaller Young modulus we have large difference of specific deformations between elastic and plastic model. This difference becomes smaller with increasing Young modulus. The level of specific deformation of steel lining is limited to $3.5 \%$ (1000 cycles) [9]. From Fig. 6 we see that condition is satisfied if Young modulus is $15 \mathrm{GPa}$ or greater.

\section{References}

[1] R. Glamheden and P. Curtis, Excavation of a cavern for high-pressure gas storage of natural gas, Tunneling and
Underground Space Technology 21 (2006) 56-67,

[2] J. Johansson, High pressure storage of gas in lined rock caverns-cavern wall design principles, Licentiate Thesis, Div. of Soil and Rock Mech., Royal Institute of Technology, Stockholm, 2003.

[3] P. Jelušič, Feasibility analysis of high pressure underground natural gas storage, Diploma Thesis, 2009.

[4] J. Jaeger and N. Cook, Fundamentals of Rock Mechanics, University of Minnesota, 1969, pp.127-128,

[5] PLAXIS Version 8 Material Models Manual.

[6] Hoek and Evert, Practical rock engineering-an ongoing set of notes, available online at: http://www.rocscience.com.

[7] E. Hoek, C. T. Carranza-Torres and B. Corkum, Hoek-Brown failure criterion (2002 ed.), in: Proc. North American Rock Mechanics Society meeting in Toronto, 2002.

[8] E. Hoek and M. S. Diederichs, Empirical estimation of rock mass modulus, International Journal of Rock Mechanics and Mining Sciences 43 (2006) 203-215.

[9] EN 1993-1: Eurocode 3: Design of steel structures, 2005. 